\title{
Clinical Reasoning: A 66-year-old woman with seizures and progressive right-sided weakness
}

Béatrice Deschênes St-Pierre, MD, MSc, Anne-Marie Trudelle, MD, and Robert Jr Laforce, MD, PhD

Neurology ${ }^{\circledR}$ 2018;90:e435-e439. doi:10.1212/WNL.0000000000004892

\section{Section 1}

A 66-year-old woman was brought to the emergency department for tremor in her right lower extremity followed by loss of consciousness and movements of all 4 limbs. Upon arrival, we witnessed a tonic-clonic seizure with left gaze deviation. She was treated with lorazepam and phenytoin.

The patient reported that a few hours' prior to her seizure, she felt spasms in her right leg. She also reported a minor fall with head trauma 2 weeks before.

Her medical and surgical history included vitreous detachment and polyp resection. She was on estradiol $10 \mu \mathrm{g}$ patch/3 days. She denied tobacco, alcohol, or drug use and had a stable sexual partner.

On examination, she had bitten the right side of her tongue, she had absent dorsiflexion of the right ankle (0/5), and she had a right Babinski sign.

\section{Questions for consideration:}

1. What is your differential diagnosis at this point?

2. Where do you localize the lesion?

\author{
Correspondence \\ Dr. Laforce \\ robert.laforce@fmed. \\ ulaval.ca
}

GO TO SECTION 2 


\section{Section 2}

The differential diagnosis of seizure in the seventh decade encompasses multiple etiologies: vascular (ischemic stroke, hemorrhage, vascular malformation), infectious (meningitis, encephalitis, abscess), neoplastic (primary, metastatic), as well as toxic or metabolic abnormalities (endocrine, electrolyte disturbance). Her recent head trauma also evokes possible intracranial bleeding (subdural hematoma).

Weakness in the right lower extremity and a Babinski sign raise the suspicion of a lesion in the left homunculus. The gross motor deficit (paresis) is more likely related to a lesion in the primary motor cortex (precentral gyrus) than a lesion in the associative cortex or supplementary motor area. Weakness combined with upper motor neuron signs could also be explained by a lesion in subcortical white matter (corona radiata, posterior limb of internal capsule), in lower subcortical structures (basal ganglia), or in the brainstem (midbrain, pons, medulla). However, this would not typically be associated with seizures.

Initial laboratory investigations included a complete blood count, electrolytes, blood urea nitrogen, creatinine, basic coagulation tests, liver function tests, thyroid-stimulating hormone, troponins, blood glucose, and glycosylated hemoglobin. The only abnormality was neutrophilic leukocytosis (white blood cells 17.7, neutrophils 14.1). Noncontrast head CT showed subtle periventricular white matter hypodensities with a confluence in the right frontal region.

On the following day, the patient's weakness had spread to the whole lower right extremity but appeared less severe $(4+/ 5$ proximal, 3/5 distal). Gadolinium-enhanced brain MRI revealed a lesion in the left posteroinferior prerolandic gyrus with loss of gray-white matter differentiation and a discrete halo of hemosiderin (figure 1, A-C).

EEG monitoring did not show any epileptiform activity and the patient had sinus rhythm on cardiac telemetry. On the fourth day, her weakness worsened ( $3 / 5$ proximal, $0 / 5$ distal). Brain MRI was repeated and revealed progression of the lesion in the left posteroinferior prerolandic gyrus with mass effect, edema, and probable laminar necrosis. An autoimmune panel, lumbar puncture, and HIV and syphilis testing were performed.

The patient was transferred to a tertiary neurology center for further investigations. Another brain MRI was performed 4 days later and showed progression of the edema, microhemorrhages, and new gadolinium-enhanced focal cortical lesions (figure 1, D-F). Contrast-enhanced CT of head, neck, thorax, abdomen, and pelvis showed ectasia of the left internal carotid artery $(11 \mathrm{~mm})$ and a uterine fibroma.

Two days later, the patient complained of right upper extremity weakness and her examination showed upper limb weakness ( $3 / 5$ proximally and $1 / 5$ distally). Brain MRI revealed ischemia in the left posteroinferior prerolandic gyrus.

\section{Questions for consideration:}

1. What is the differential diagnosis of a rapidly progressing ischemic/hemorrhagic lesion located in the posteroinferior prerolandic gyrus?

2. What further investigations would you perform at this stage? 
Figure $1 \mathrm{MRI}$ of the brain

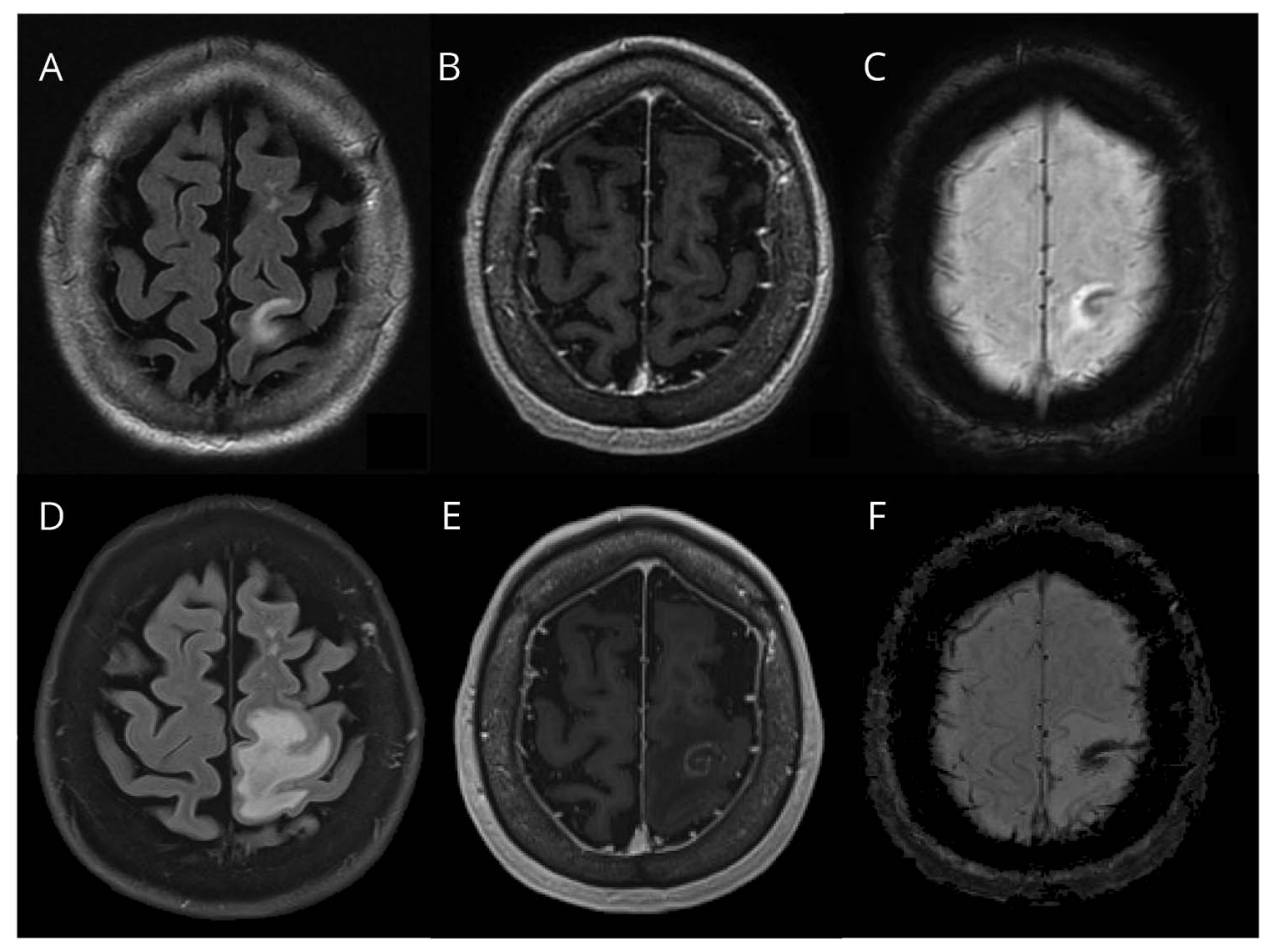

Day 2 of the patient's hospitalization: (A) fluid-attenuated inversion recovery (FLAIR), (B) gadolinium-enhanced, and (C) gradient-echo imaging. Day 8 of the patient's hospitalization: (D) FLAIR, (E) gadolinium-enhanced, and (F) susceptibility-weighted imaging.

GO TO SECTION 3 


\section{Section 3}

The halo of hemosiderin in the precentral gyrus on the first MRI suggests nonacute bleeding (usually greater than 2 to 4 weeks) while another MRI, performed less than a week later, indicates evidence of progression with edema and laminar necrosis. The 3 main differential diagnoses are vasculitis, hemorrhagic glial tumor, and venous structural abnormality or thrombosis. Rapid progression makes tumor less likely while ischemia on subsequent imaging supports an underlying vascular mechanism.

Brain angiography was performed (figure 2) and revealed an arteriovenous shunt: a direct fistula from a frontal branch of the middle meningeal artery to a subdural vein. The vein was enlarged (twice the diameter of the artery) and drained in the superior sagittal sinus. The venous abnormality on angiogram was located adjacent to the region of parenchymal abnormality observed on MRI. The most likely diagnosis was a dural fistula, with partial thrombosis of the cortical vein and secondary venous ischemia.

Due to numerous anatomic variations in the patient's neck vasculature, it was not possible to achieve embolization during angiography. Neurosurgery was consulted and performed a craniotomy during which an intradural vein communicating with a cortical vein was found and coagulated. The cortical vein became blue and nonpulsating, hence demonstrating that it was supplied only by the arteriovenous fistula.

In the weeks following surgical intervention, the patient's right-sided weakness rapidly improved. After months of outpatient rehabilitation, she was able to ride her bicycle and started running again. She continued to report slight residual weakness in the right foot.

\section{Discussion}

Dural arteriovenous fistulae (DAVF) are rare lesions characterized by an anastomosis between a meningeal artery and a cortical vein or a dural venous sinus. The normal antegrade flow through cortical veins is reversed, causing venous hypertension, which can produce hemorrhage when arterialized veins rupture. These pathologic connections are often located at the transverse sigmoid junction, but can be found in other locations, including cavernous sinus, superior sagittal sinus, anterior cranial fossa, and tentorium. ${ }^{1}$ They usually present in older adult patients, 50-60 years old. ${ }^{2}$ They can occur following traumatic brain injury, infection, craniotomy, tumor, or sinus venous thrombosis, but they are commonly idiopathic. ${ }^{2-4}$ The most accepted pathologic hypothesis is progressive stenosis or occlusion of dural venous sinus.

DAVF can be an asymptomatic incidental finding. They can present with mild symptoms (e.g., paresthesia) or severe symptoms (e.g., weakness) of nonhemorrhagic neurologic deficits (NHND). NHND progresses over days to weeks, as a result of ischemia due to venous hypertension, with various focal and nonfocal neurologic symptoms. Intracranial haemorrhage (ICH) occurs when an arterialized vein ruptures or when there is hemorrhagic transformation within an area of cortical venous hypertension. It usually produces a suddenonset headache with substantial neurologic deficits related to the location of the bleeding. ${ }^{1}$

Brain MRI can demonstrate venous dilation, ectasia, thrombosis, occlusion, or arterialization (flow-void). Any serpiginous

Figure 2 Brain angiography

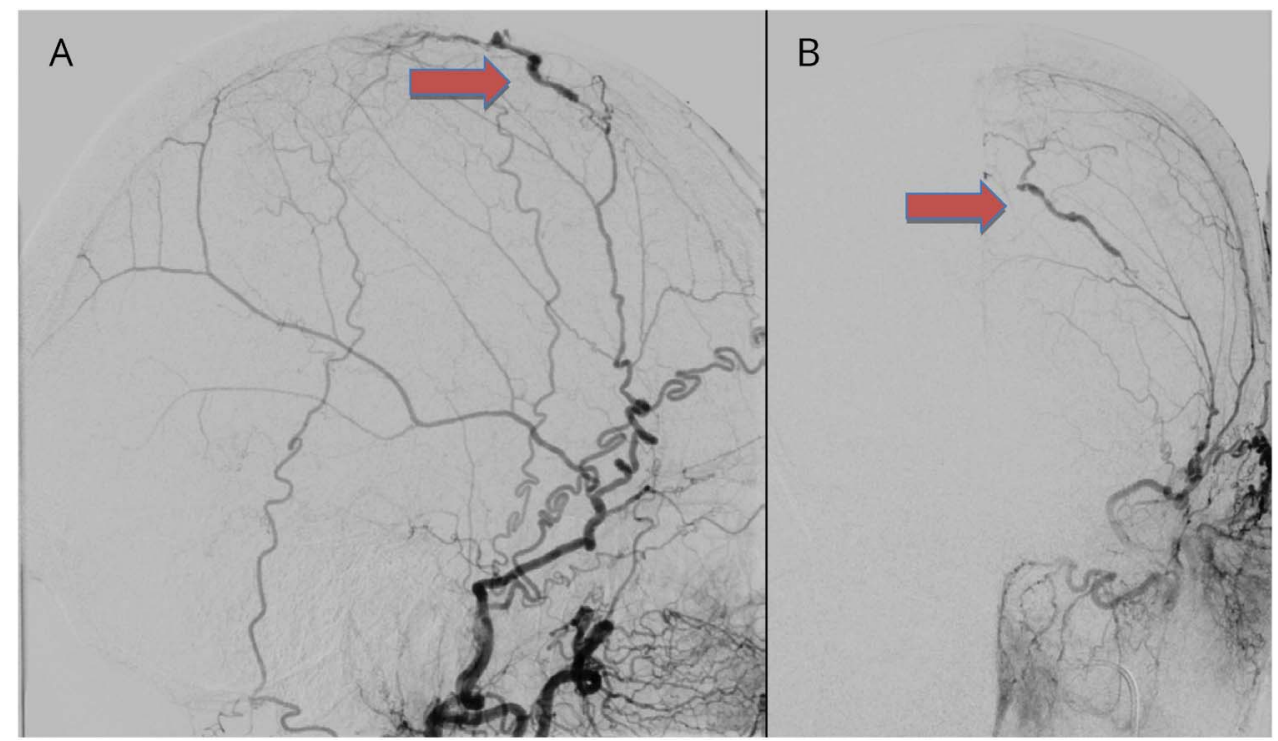

Injection of the left carotid artery reveals an arteriovenous shunt; that is, a direct fistula from a frontal branch of the middle meningeal artery (A) to a subdural vein (B) (arrows). 
vessel near a venous sinus mandates cerebral angiographic evaluation, which is the gold standard for DAVF diagnosis. Head CT can be normal or show secondary bleeding or vasogenic edema.

Three main classifications exist (Zipfel, Borden-Shucart, and Cognard), but clinically, the main determinant of the management is the presence/absence of cortical venous drainage (CVD). Low-grade DAVF (without CVD) have an annual neurologic event rate of $0.6 \%$ and annual mortality rate of $0.0 \%{ }^{6}$ High-grade DAVF (with CVD) have a very aggressive course with annual neurologic event rate of $15.0 \%$ and annual mortality rate of $10.4 \% .^{7}$ The presence of venous ectasia increases the risk of hemorrhage. ${ }^{8}$ New or recurring neurologic symptoms in a patient with a low-grade DAVF should raise the suspicion of a conversion to high-grade DAVF $(0.8 \%$ per year $\left.{ }^{9}\right)$. Another important prognostic factor is the presence/absence of haemorrhage. NHND has a much better prognosis when left untreated than $\mathrm{ICH}$ : annual rate of new neurologic event of $19.0 \%$ compared to $1.4 \%$ and annual mortality rate of $3.8 \%$ compared to $0.0 \%{ }^{10}$

Management can be divided into 3 options. First, a DAVF with CVD presenting with ICH or NHND should have urgent treatment. Second, a DAVF with CVD in patients who are asymptomatic or have benign symptoms should be treated if the individual has a significant life expectancy and no comorbidities. Third, a DAVF without CVD can be treated if symptoms are severe and affect the patient's quality of life. Treatment aims to clear CVD and, if possible, obliterate DAVF by endovascular embolization or surgical disconnection.

In short, DAVF is a treatable condition, which can present with a wide variety of neurologic symptoms. MRI often demonstrates findings that raise suspicion of a vascular lesion or tumor. Clinicians should consider this condition in the differential diagnosis and rapidly refer patients for angiography when appropriate.

\section{Author contributions}

Béatrice Deschênes St-Pierre: conception and design of the article, analysis and interpretation of data, draft and revision of the article. Anne-Marie Trudelle: analysis and interpretation of data, revision of the article. Robert Jr Laforce: conception and design of the article, analysis and interpretation of data, revision of the article.

\section{Acknowledgment}

The authors thank Dr. Roger McKelvey for reviewing the article.

\section{Study funding}

No targeted funding reported.

\section{Disclosure}

The authors report no disclosures relevant to the manuscript. Go to Neurology.org/N for full disclosures.

\section{References}

1. Reynolds MR, Lanzino G, Zipfel GJ. Intracranial dural arteriovenous fistulae. Stroke 2017;48:1424-1431.

2. Brown RD, Wiebers DO, Nichols DA. Intracranial dural arteriovenous fistulae: angiographic predictors of intracranial hemorrhage and clinical outcome in nonsurgical patients. J Neurosurg 1994;81:531-538.

3. Brown RD, Flemming KD, Meyer FB, Cloft HJ, Pollock BE, Link ML. Natural history, evaluation, and management of intracranial vascular malformations. Mayo Clin Proc 2005;80:269-281.

4. Vellimana AK, Daniels DJ, Shah MN, Zipfel GJ, Lanzino G. Dural arteriovenous fistulas associated with benign meningeal tumors. Acta Neurochir 2014;156:535-544.

5. Letourneau-Guillon L, Cruz JP, Krings T. CT and MR imaging of non-cavernous cranial dural arteriovenous fistulas: findings associated with cortical venous reflux. Eur J Radiol 2015;84:1555-1563.

6. Satomi J, van Dijk JM, Terbrugge KG, Willinsky RA, Wallace MC. Benign cranial dural arteriovenous fistulas: outcome of conservative management based on the natural history of the lesion. J Neurosurg 2002;97:767-770.

7. van Dijk JM, terBrugge KG, Willinsky RA, Wallace MC. Clinical course of cranial dural arteriovenous fistulas with long-term persistent cortical venous reflux. Stroke 2002;33:1233-1236

8. Gross BA, Du R. The natural history of cerebral dural arteriovenous fistulae. Neurosurgery 2012;71:594-602; discussion 602-603.

9. Shah MN, Botros JA, Pilgram TK, et al. Borden-Shucart type I dural arteriovenous fistulas: clinical course including risk of conversion to higher-grade fistulas. J Neurosurg 2012;117:539-545

10. Strom RG, Botros JA, Refai D, et al. Cranial dural arteriovenous fistulae: asymptomatic cortical venous drainage portends less aggressive clinical course. Neurosurgery 2009; 64:241-247; discussion 247-248. 


\section{Neurology}

\section{Clinical Reasoning: A 66-year-old woman with seizures and progressive right-sided weakness}

Béatrice Deschênes St-Pierre, Anne-Marie Trudelle and Robert Laforce, Jr

Neurology 2018;90;e435-e439

DOI 10.1212/WNL.0000000000004892

This information is current as of January 29, 2018

\section{Updated Information \&} Services

References

Subspecialty Collections

Permissions \& Licensing

Reprints including high resolution figures, can be found at: http://n.neurology.org/content/90/5/e435.full

This article cites 10 articles, 2 of which you can access for free at: http://n.neurology.org/content/90/5/e435.full\#ref-list-1

This article, along with others on similar topics, appears in the following collection(s):

All Epilepsy/Seizures

http://n.neurology.org/cgi/collection/all_epilepsy_seizures All Oncology

http://n.neurology.org/cgi/collection/all_oncology

Arteriovenous malformation

http://n.neurology.org/cgi/collection/arteriovenous_malformation Cerebral venous thrombosis

http://n.neurology.org/cgi/collection/cerebral_venous_thrombosis

Information about reproducing this article in parts (figures,tables) or in its entirety can be found online at:

http://www.neurology.org/about/about_the_journal\#permissions

Information about ordering reprints can be found online:

http://n.neurology.org/subscribers/advertise

Neurology ${ }^{\circledR}$ is the official journal of the American Academy of Neurology. Published continuously since 1951 , it is now a weekly with 48 issues per year. Copyright @ 2018 American Academy of Neurology. All rights reserved. Print ISSN: 0028-3878. Online ISSN: 1526-632X.

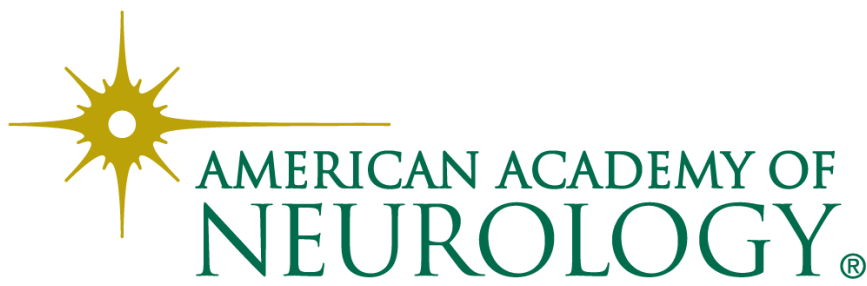

